\title{
The Ethical Dilemma of Software Piracy: An Inquiry from an Islamic Perspective
}

\author{
Hewa Majeed Zangana ${ }^{1}$ \\ Imad Fakhri Al-Shaikhli \\ Yuliana Isma Graha ${ }^{3}$ \\ e-mail : hewa.majeed@yahoo.com,imadf@iium.edu.my,iz@raharja.info
}

Diterima : 19 Mei 2013 / Disetujui: 23 Agustus 2013

\begin{abstract}
Software piracy in the Muslim countries is a prevailing issue. It has been estimated based on BSA by 2009 that more than 90\% of software in Yemen is pirated, followed by Libya 88\%, Indonesia 86\%, and Iraq 85\%. UAE has the lowest rate for software piracy, which is 36\%. While in the Middle East area, the piracy rate is around 59\% with total commercial value of \$2,887 Million. Furthermore, the software piracy remains a critical issue in Asia Pacific, with the region accounting for the highest dollar losses in the world from the use of unlicensed software. The survey of software piracy around the world, which is collaboration between the Business Software Alliance (BSA) and IDC, indicates that software piracy on personal computers in the Asia Pacific region in November 2009 was 61 percent, worth 15,000 million U.S. dollars (BSA, 2009; IDC Global PC). The purpose of this study is to understand the software piracy from Islamic perspective and finding the recommendations, solutions of this problem to deter software piracy as much as possible. Focusing on the Islamic rule, evidence and argument relating to copyright infringement especially software piracy in the Islamic world; additionally, the effect of software piracy.
\end{abstract}

Key Words: Software Piracy, Islamic Perspective.

\section{INTRODUCTION}

1. Department of Information System,

KICT/ International Islamic University Malaysia, Malaysia

2. Department of Computer Science,

KICT/ International Islamic University Malaysia, Malaysia

3. Mahasiswa Jurusan Tehnik Informatika, STMIK Raharja

Jl. Diponegoro 52-60, Salatiga 50711, Indonesia 
With the rapid changes in the global business environment and the Western chance in expanding markets, protection of intellectual property and prevention of software piracy are among the most important international problems facing the software industries. The PC software industries estimates that it loses \$3 billion a year to illegal copies in the US, $\$ 5.3$ billion a year in Europe, and several billion more in East Asia markets.

Digital piracy is heavily debated in media today. Close to all new software, music and movies are made available on the Internet by people who feel that information should be free. Piracy has been around since the dawn of software but the industry has been rather slow to react. Anti-piracy groups have been founded and funded by the manufacturers of software and digital media and they have shown quite good results when combating piracy within corporations.
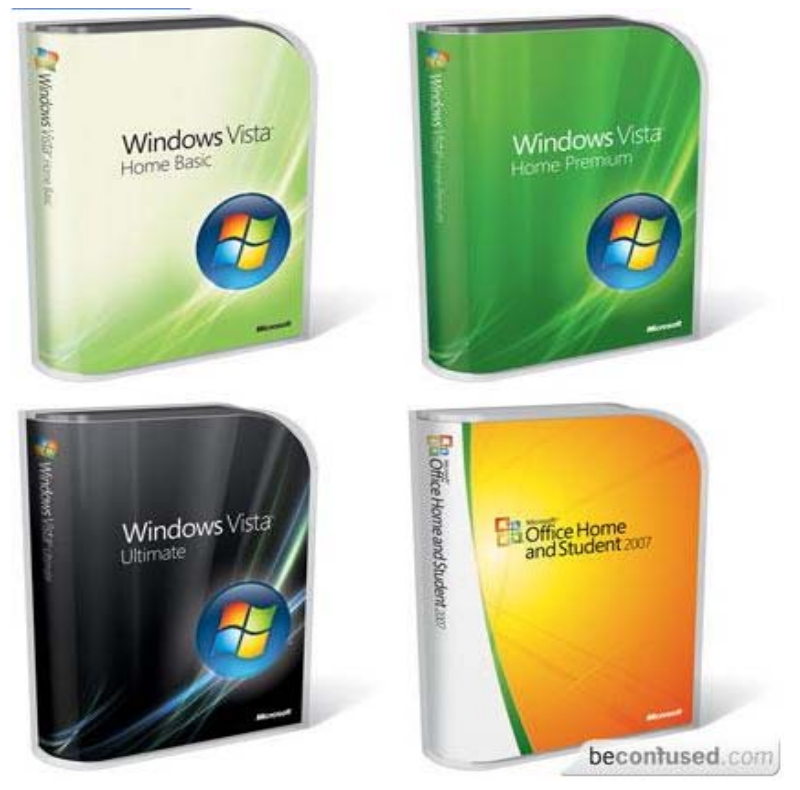

Figure 1: Microsoft Software Products

Software piracy has reached an epidemic level in the World. Many countries need or even don't have a modern copyright law, or they do not enforce it. The US and Western countries are putting pressure on those countries to introduce and enforce legislations to improve their intellectual property protection.( This report evaluates the current situation and important factors concerning software piracy. Such as what is software piracy? Its history, types, origins and finally a proposed 
solution. Mainly focusing, on the Islamic perspective as a motivation for writing this paper.

\section{THE HISTORY OF DIGITAL \& SOFTWARE PIRACY}

When personal computers made their entry on the market in the late 1970's, the notion of software was only a few years old. Therefore there was no established legislation concerning software although one could argue that the software was protected in the same way as a published entity or as intellectual property. Before the arrival of personal computers another form of piracy played a major part in society, "Bootlegging” "Copying” of records was commonplace but not in the same extent as today with CD- burners and peer-to-peer networks.

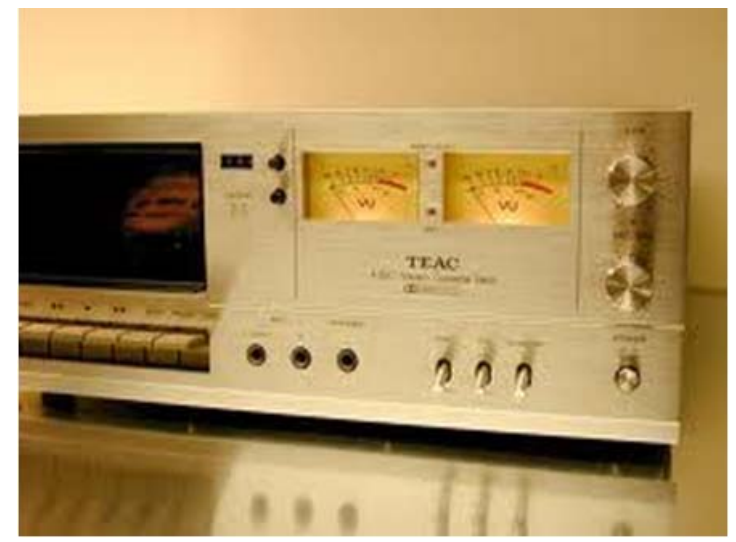

Figure 2: Cassette Deck

The arrival of the cassette deck was another major leap towards widespread piracy. Music could now easily be copied and distributed in the small format that cassette tapes offered. Several of the early personal computers also used cassettes as storage devices. The software piracy scene flourished at the time and cassettes were swapped and copied, many times because of the prices but also because of the lack of availability from retailers.

The next storage device that followed was the floppy disc. In the beginning they could only contain around $170 \mathrm{~KB}$ of data but as time passed, the floppy discs grew to a capacity of $1,44 \mathrm{MB}$. This increase in capacity was joined by a new generation of personal computers. The most popular among them was the Amiga, especially the Amiga 500. Floppy discs had by this time become standard and were widely used to spread copies of games and software. 


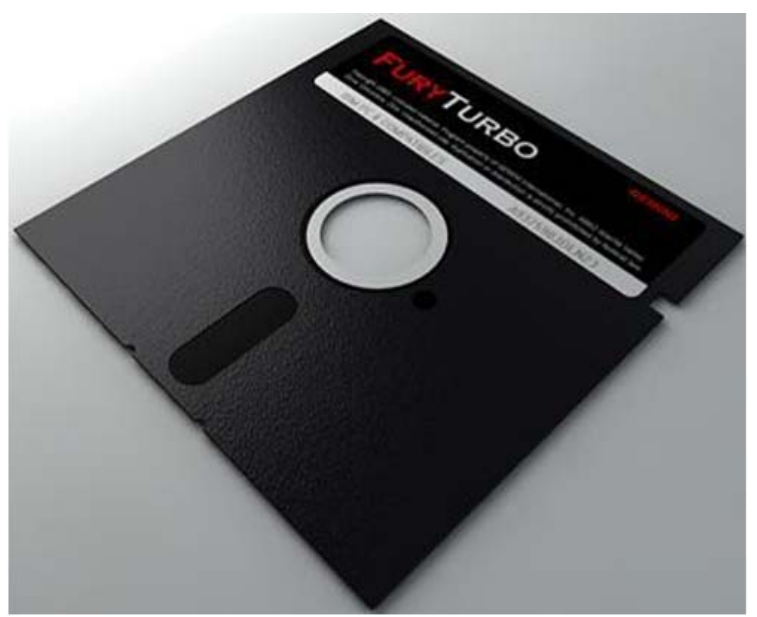

Figure 3: Early 170 KB Floppy Desk

The movie industry feared for their very existence when the VCR (Video Cassette Recorder) was first released in 1977. Many argued that this was the end for the movie industry, especially when Sony won a

landmark case in 1984 which established video recorder owners' right to tape films broadcast on TV. Instead, the VCR created a huge new market for video sale and rental which has remained prosperous up to this date.

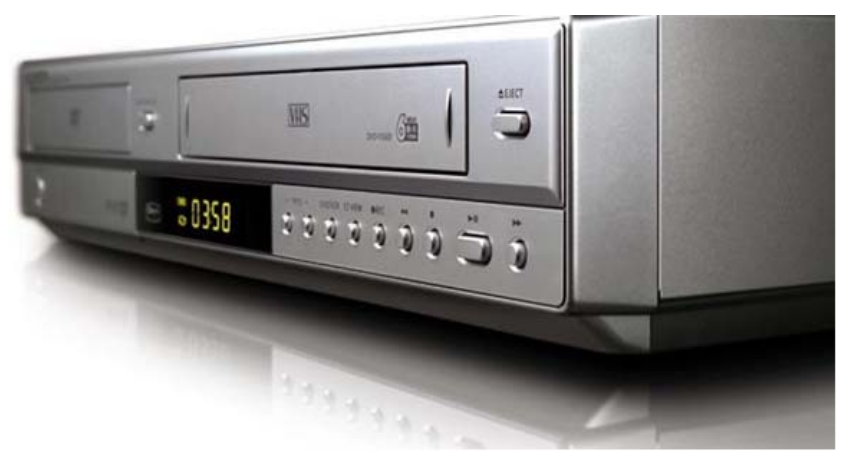

Figure 4: VHS Tape Player (VCR)

During this period in time cracking groups emerged in large numbers and they used as well as mailing and personally BBSs (Bulletin Board Systems) to trade software trading floppy discs. A vast majority of the software in end users possession 
was pirated and it was widely accepted among the users that duplicating software was acceptable. Computers had gone down in price and modems were also affordable. BBSs became the meeting place of all young people with an interest in computers. Piracy was common, but the BBSs were also a perfect place for people to exchange ideas and gain knowledge of very narrow fields by discussing with other users.

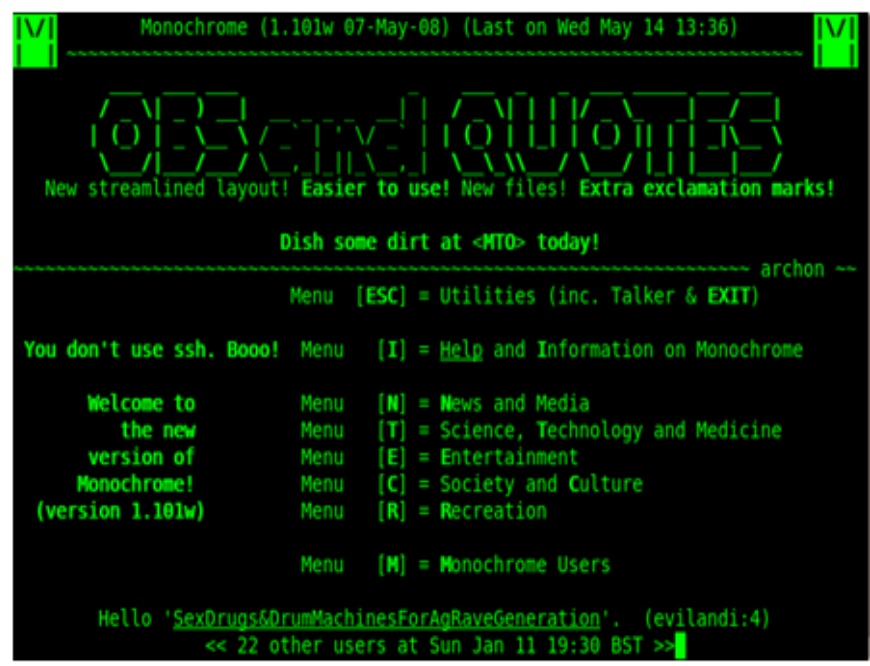

Figure 5: (BBS) Bulletin Board Systems Interface

BBSs had their golden years during the 1980's and they emerged in large numbers especially during the latter part of the decade. While computer software was pirated in a larger extent than ever before, the music industry released a new system called CD (Compact Disc). ( The sound quality had improved a lot and cassette tapes were starting to lose ground. CDs were difficult to copy since CDwriters weren't yet available in every home. On the contrary, they were very expensive and the majority of pirated CD's were sold by pirates who produced large quantities of popular titles.

The CD proved to be a very cost effective reliable storage system and was soon incorporated in the computer world. Instead of using several floppy discs, a CD could now be used to distribute software. Personal Computers had now moved in to the next generation consisting of Macintosh and a collection of different machines under the name PC. They had been around for quite some time already but Macintosh's and PC's didn't get very common in homes until now, when the prices were affordable. 


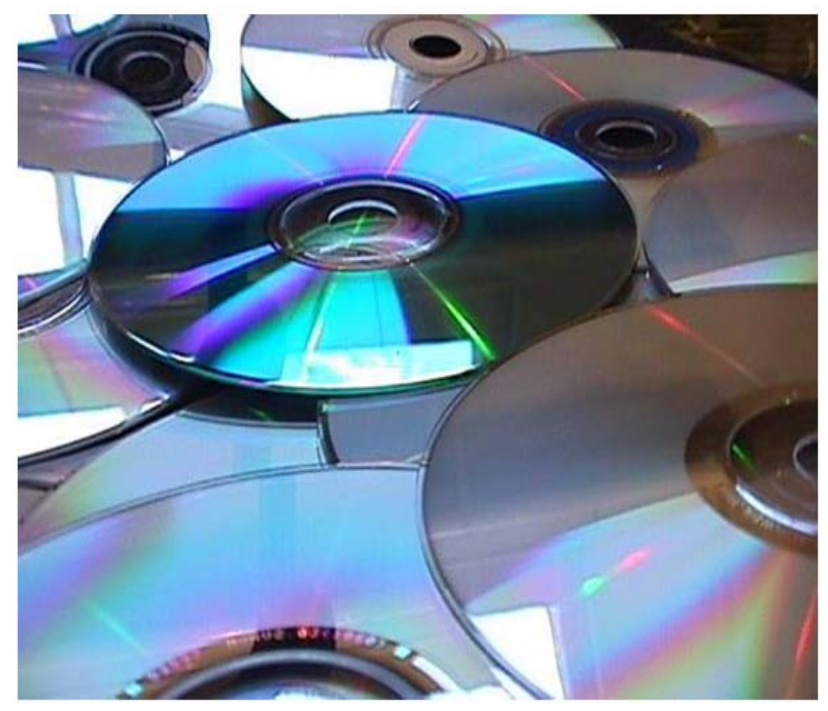

Figure 6: The Compact Disc (CD)

In the mid 1990's, CD-writers for home use started to appear and another revolution in terms of piracy began. Internet started to find its way into people's homes and MP3 songs were steadily on the move. The BBS's which earlier had served as rather local meeting places now started to transfer to the Internet to join forces with all the other BBS's. CD's were copied more and more frequently and the industry had a hard time protecting its products.

Audio CD's lacked any kind of copy protection and a lot of people borrowed records and copied them in the privacy of their own homes. Copy protection for computer software was common at the time, which didn't discourage the now more organized cracking groups. Internet had become well developed and the groups could move substantial amounts of data over the web, instead of relying on swapping or mailing floppy discs and CD-ROM's.

Piracy had up to this place been common, and everyone with a slight interest in computers had been able to get hold of illegally duplicated software. The event that really got the ball moving was the release of Napster, a program written by a student named Shawn Fanning that allows users to share music with each other.

It didn't take long until Napster was the word on everyone's mouth and the amount of downloaded MP3's was larger than ever. The music industry stood flabbergasted and struggled to resolve the problem. Meanwhile, record sales surprised everybody as they kept pointing up with the exception of singles that declined. 


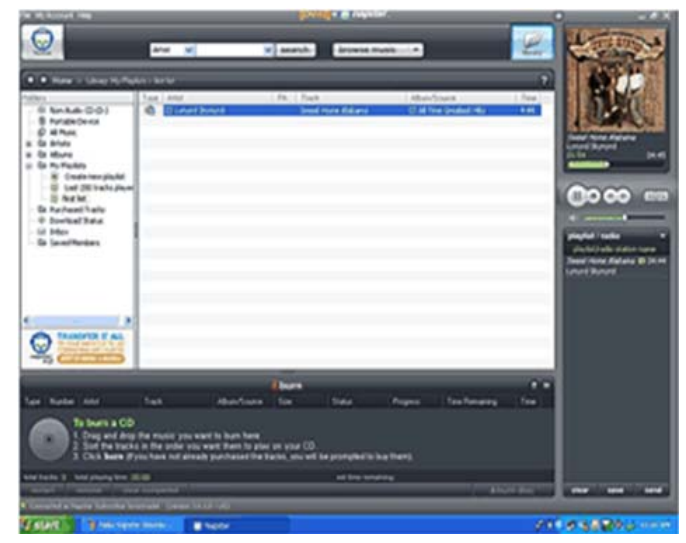

Figure 7: Napster Interface

Napster paved the way for several clones and more sophisticated types of file-sharing systems. These became grouped together under the name Peer-to-peer. This meant that files were swapped between users in a decentralized system where no illegal data was hosted on a centralized server. Peer-to-peer has since continued to grow and is, as we speak, the most popular method of file-sharing amongst the public. Lately, movies have become more and more popular and with broadband widely available, downloading a movie often takes a shorter amount of time than to go rent one.

With the release of DVD-writers, copying of DVD movies has started to take off. This has opened up a new market for copy protection systems since the original scrambling system for DVD (CSS) was cracked by a Norwegian boy who wanted to create an open-source software DVD-player for Linux.
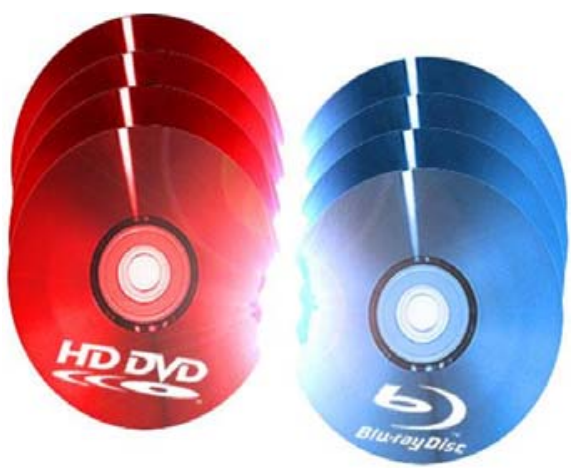

Figure 8: Digital Video Disc (DVD) 


\section{WHAT IS SOFTWARE PIRACY?}

Software piracy is the unauthorized copying, use, or distribution of software product, protected by Copyright Law. On average, for every authorized copy of PC software in use, at least one unauthorized copy is made. In some countries, up to 99 unauthorized copies are made for every Software piracy authorized copy in use.

Software Piracy harms all software companies and ultimately the end-user. It results in higher prices for licensed users, reduced levels of support, reduced investment in the development of new products and a reduction in product support and training.( Piracy is considered a living nightmare for all software publishers, regardless of their size. Software developers spend literally years developing software for the public to use. A portion of purchasing original every dollar spent in software is funneled back into research and development so that better, more advanced when software products can be produced.

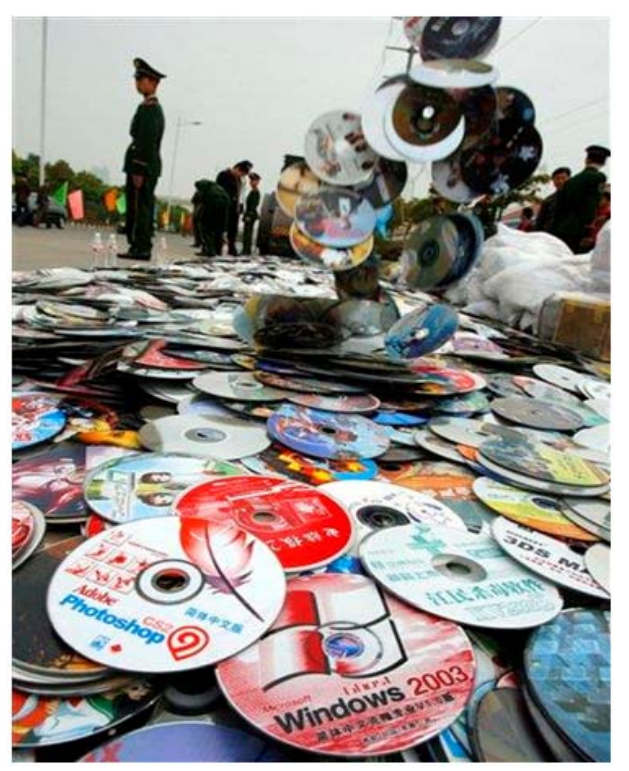

Figure 9: Pirated DVDs Prepped For Disposal

When the Software is pirated the developer receives no compensation whatsoever. Software piracy threatens the continued growth of not only the western based software publishing industry, but also software developers around the world. 


\section{TYPES OF SOFTWARE PIRACY}

According to Business Software association (BSA) there are five common types of software piracy. Understanding each one of them will help users avoid problems associated with illegal software issues.

\section{End User Piracy}

This occurs when a company employee reproduces copies of software without authorization, such as using one licensed copy to install a program on multiple computers, or Copying disks for installation and distribution, for example; when extra copies of a program are made within an organization for employees to use. Disk swapping among friends and associates outside of a business environment is also included in this category.

\section{Client-Server Overuse}

This occurs when too many employees on a network are using a central copy of a program at the same time. This form of piracy occurs when copyrighted software is downloaded to users connected via a modem to an electronic bulletin board.( Piracy of copyrighted software via an electronic bulletin board should not be confused with sharing public domain software or providing shareware which is a software that may or may not be copyrighted but is specifically offered by the author for nearly unrestricted use, including copying or sharing with others.

\section{Internet Piracy}

This occurs when software is downloaded from the Internet. The same purchasing rules should apply to online software purchase as for those bought in traditional ways.

\section{Hard-Disk Loading}

This occurs when a business who sells new computers loads illegal copies of software onto the hard disks to make the purchase of the machines more attractive. Some computer dealers load unauthorized copies of software onto the hard disks of the computers they offer for sale as an incentive for an end-user to purchase a computer from that particular dealer.

\section{Software Counterfeiting}


This type of piracy is the illegal duplication and sale of copyrighted material with the intent of directly imitating the copyrighted product. This type of illegal duplication and sale of copyrighted software, often in a form designed to make the product appear legitimate.( Software counterfeiters operate purely for profit, and money always changes hands. Software counterfeiting also occurs when obviously illegitimate products such as those containing inferior or hand- written labels folded into a plastic bag are sold over the counter or on the street.

\section{WHY SOFTWARE PIRACY?}

The simplest, and most direct, answer is because it is easy. With the almost complete elimination of “product locks” in the mid-1980's due to logistical and support concerns, creating duplicate copies of a software program became a relatively easy task. Using a few simple keystrokes, any functioning PC had - and has - the ability to create a duplicate copy of a software program in a matter of minutes.

However, simplicity is not the only answer. Inadequate copyright laws, lack of government commitment to enforcement, and unfamiliarity with the advantages of original software use are among the factors contributing to the high rates of software piracy around the world.( Software piracy not only denies the software developer its rightful revenue, it also harms the local and national economies. Fewer legitimate software sales result in lost tax revenue and decreased employment. Software piracy greatly hinders the development of local software communities. If software publishers cannot sell their products in the legitimate market, they have no incentive to continue developing programs. Many software publishers simply won’t enter markets where the piracy rates are too high because they will not be able to recover their development costs.

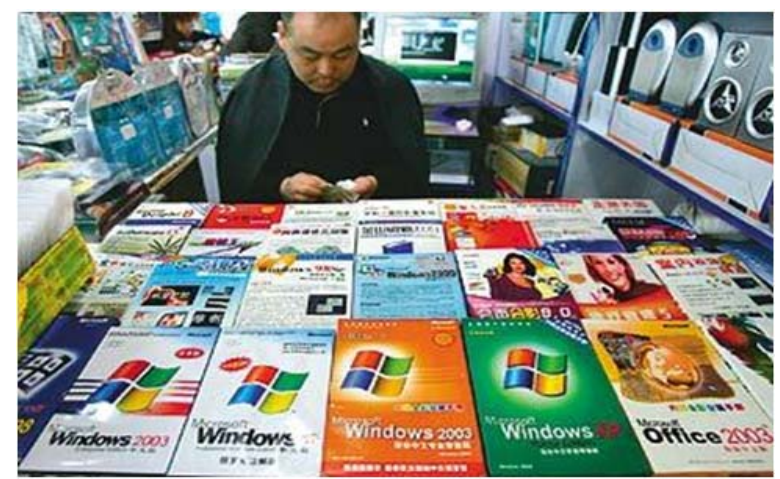

Figure 10: Pirated \& Cheep Software 
In addition to the fact that technology has made software piracy as simple as connecting the Internet, downloading the application and burning the application to a CD, there are other reasons why software is pirated.( Crackers like to resell the application through an online auction at a substantially reduced price or take the time to increase their personal expertise on a specific application and provide knowledge transfer for financial gain.

Crackers can pirate applications to steal features and include these features in their own products. Ex-employees can have issues with a specific coworker or their ex-employer and break an application, distributing the software for free or perhaps gaining notoriety themselves by damaging the credibility of the manufacturer or the application.

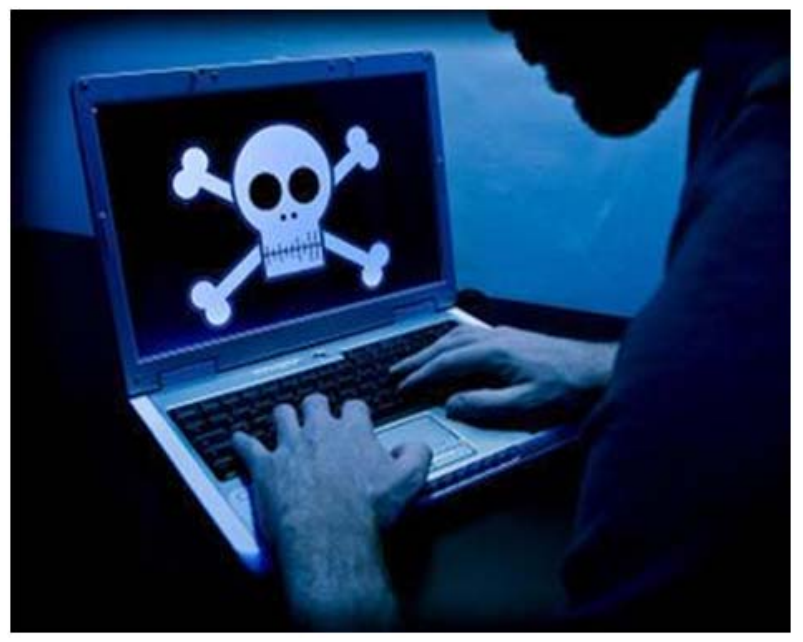

Figure 11: Crackers Can Cause Some Serious Damages

Individuals and organizations may be unwilling to pay what they perceive as high prices for additional licenses or there may be no money left in the budget and they feel a need to copy or crack the application. The application may be copied for a short-term solution to an existing problem such as a project overrun of scope and budget. In this case, individuals or organizations can copy and deploy the software, which allows the hiring of additional resource(s) to complete the project within scope.

Hackers perceive breaking the application as a personal challenge and get personal satisfaction when they've hacked the application. Hackers have broken into applications to highlight the applications weakness in hopes that the software developer rectifies the identified weaknesses and produces a more secure product. 


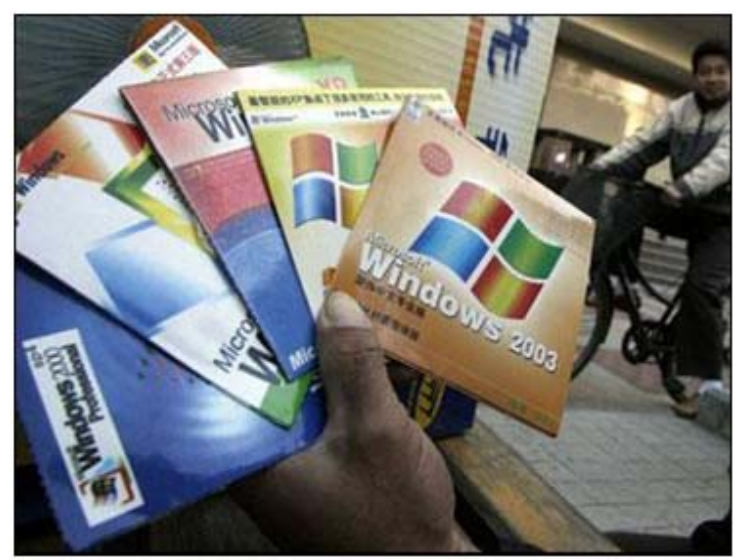

Figure 12: Pirated Software Ready for Sale

Convenience is often a factor for individuals and organizations that will copy an application for immediate use, making the copying process more convenient than obtaining a new license. While believing this one off event will not have any ethical or financial impact, the accumulation of these events leads to severe piracy issues worldwide.

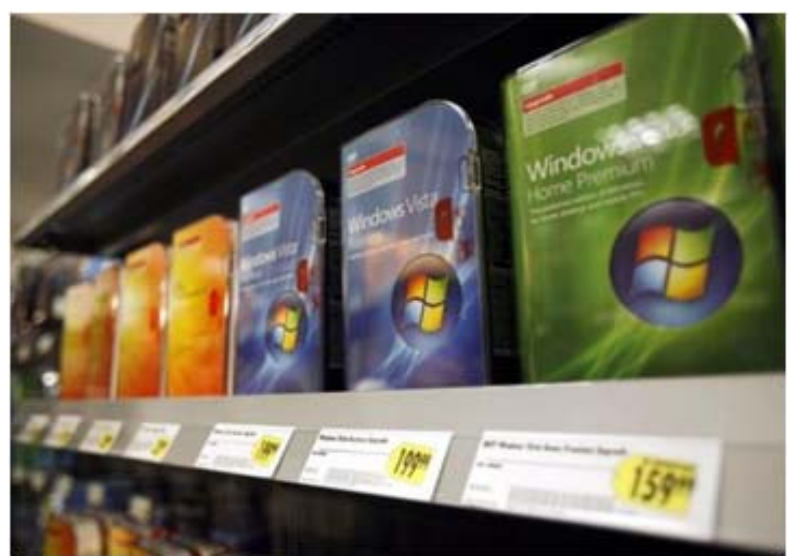

Figure 13: Original Software \& High Prices Dilemma

\section{ISLAMIC WORLDVIEW}

On a very breezy evening, an old man walking from the north passed by a 
group of children who were sitting on a wooden bench. The children who were busy talking to themselves did not notice the poor old man. Suddenly, the old man approached them and asked a very simple question, while pointing his forefinger to a big tree: "What do you see?” The first child answered: "It is a tree”. The old man nodded his head. Then, the second child answered: "It is a tree which will die after some times". The old man smile and nodded his head again to agree with him. Then the last child, after thinking for a while, he opened his mouth and said: "It is a tree. It has been created by the Almighty. The rest of its life has been spent to worship its Creator until one day when the time has come, it will die, leaving this world. Likewise the tree, the same goes to human like us. The only different is that there will be a life after our death where all our actions and deeds in this world will be counted". The old man was very surprised and tapped the child's shoulder and said: "Yes, you are true!"

What makes the children gave different answers to the old man? Is it because the third child is more mature than the others? Maybe, but let assume that their level of maturity are the same since they are just children of a same age. One reason for that is what Chapra[10] called worldview. Worldview is "a set of implicit and explicit assumptions about the origin of the universe and the nature of human life". In other words, worldview is "the way in which a person sees and explains the world and his place in it" [14]. As a building with its foundation, worldview serves as an essential base for man since the way he thinks, acts, behaves and his reflections towards everything are directly influenced by his worldview [14]; [10]. The different answers provided by the 3 children previously might also as a result of different worldview. Meanwhile, the sources of worldview might vary. Some acquires it from religions [14]; [7], while others perhaps inherited from their ethnics which they belong to or maybe they just blindly follow others. As compared to the "materialist fundamental secularism" [16] of the Western worldview, Islam sees this world from dual perspectives. In essence, "Islamic ontology presents a dual worldview, this world (universe) and the hereafter” [16].

\section{THE ISSUE OF SOFTWARE PIRACY AND COPYRIGHT INFRINGEMENT}

Software piracy in the Muslim countries is a prevailing issue. It has been estimated based on BSA by 2009 that more than $90 \%$ of software in Yemen is pirated, followed by Libya $88 \%$, Indonesia $86 \%$, and Iraq $85 \%$. UAE has the lowest rate for software piracy, which is $36 \%$. While in the Middle East area, the piracy rate is around $59 \%$ with total commercial value of \$2,887 Million. Furthermore, 
the software piracy remains a critical issue in Asia Pacific, with the region accounting for the highest dollar losses in the world from the use of unlicensed software. The survey of software piracy around the world, which is collaboration between the Business Software Alliance (BSA) and IDC, indicates that software piracy on personal computers in the Asia Pacific region in November 2009 was 61 percent, worth 15,000 million U.S. dollars (BSA, 2009; IDC Global PC).

The copyright face many problems such as software piracy. Software piracy violates existing copyright laws. Software developers protected by laws where unauthorized use and distribution of copies of software without their permission are illegal. However, the development of software copyright law has a relatively short history compared with laws that aim to protect tangible property. With tangible property, ownership is usually obvious. Physical objects must not be used without the consent of the owners (or the possessors) of the objects. There have been several legal cases concerning whether copyright and patent rights apply to computer software [13].

These problems add weight to West's suggestion that attitudes towards software piracy will not be easily changed by regulation or legislation. Intellectual property protection is expensive and inefficient. It is apparent that the problem of software piracy is not simply a legal problem, and will not be solved by legal means. Nor is it a deficiency in the protection of intellectual property generally [17].

According to many researchers, there are many factors affecting the phenomena of software piracy. Al- Fadhli [4] highlighted that among those factors are technical factors, regulatory factors, economic factors, and social/cultural factors. Therefore, the reasons and factors that may lead people to buy pirated software are; first of all, the price of pirated software; for example, cheap prices let people to buy software piracy comparing with expensive original copy, so high price of original copy contributes to the behavior of using pirated ones. Secondly, easy to get it due to availability of high storage media at low cost, and high- speed Internet connections at low cost; additionally, Software piracy is more prevalent in nations with a weak IT infrastructure since the quality of available software is lower. Next, misunderstanding from Islamic point of view about buying software piracy is one of important factors and might be a lack of monitoring from the government in Muslim countries; lack of penalties for buying pirated software is also a reason for piracy growth; for example. Finally, the most significant factors effecting software piracy is the social/cultural factors which is often viewed as a cultural practice rather than immoral action [4].

\section{INTELLECTUAL PROPERTY FROM ISLAMIC VIEWPOINT}

Muslim societies have norms and regulations that make themselves unique 
from other societies. All Muslims are requested to behave based on the Shari'a. Islam has a different view of property, which includes intellectual property rights. According to [18] and [4] there are two main tendencies among Islamic researchers concerning this issue which is traditional and contemporary? Contemporary Intellectual property issues were not addressed during the time of the Prophet and the Caliphs where Scholars at that time limited the definition of property only to tangible assets. Fatwas that have been issued does not include intellectual property like other forms of tangible property. The mainstream among traditional Islamic scholars was that intellectual works are public property. Therefore, it should not be treated like any other tangible properties.

Nowadays, Islamic society has different views on intellectual property issue concerning software copyright. Those who adhere to the position of traditional scholars refuse this concept. The researchers argue that knowledge should be available for public use and share. On the other hand, there are scholars who acknowledge intellectual property. They believed that ideas can be owned, and it is protected by the Shari'a. The scholars consider a violator benefits from the owner's work without compensating them. Therefore, they prohibit software piracy due to violation of the rights of the owner [4].

Software Piracy: An Islamic Perspective( From an Islamic Point of View, recording computer programs videos or others is forbidden unless permitted by their owner: "It is unlawful to make copies of programs whose rights are reserved to their owners except with the permission of these owners. The Prophet Said: "Muslims are bound by the conditions they set amongst themselves". [Al - Hakeem].( The Prophet Also Said: "Nobody is permitted to take the property of a Muslim unless the Muslim permits him voluntarily to do so". [Al - Daraqutny].( The Prophet Also Said: "Whoever takes hold of a lawful thing before others, he has more right to possess it than others" [Abu Dawood]. So, it is forbidden to copy these programs without the permission of their owners regardless of their being Muslims or nonMuslims. So, if the owner of these programs forbids only public copying and allows private one, the person can copy the program for private use as stipulated. But if he forbids both public and private copying it becomes then absolutely forbidden to copy these programs. Some companies put a sign meaning, "I swear not to abuse your program or use an unauthorized copy of it”. So, if the person does not comply with his oath that is a major sin. There is disagreement among contemporary Muslim scholars concerning copying CDs that whose rights are reserved by their owners. Some scholars do not legalize copying CDs. And this is the opinion of the permanent committee for Fatwa in Saudi Arabia. Their answer is as follows: 'It is not permissible to copy these CDs without permission of owners. The Prophet Mohammad PBUH Said: "Muslims are required to honor conditions that they have agreed upon". [Abu 
Dawood and Al-Saiyouti regards this Hadith as sound].(Another Hadith Reads: "A Muslim's property does not become Halal without his consent" [Al-Tirmizi who said good and sound]. A third Hadith reads: "Whoever antecedes (others) to something Halal, he becomes more entitled to possess it” [Abu Dawood, Al-Maqdisi regards it sound]. There is no difference on this ruling whether an owner is a Muslim or non-Muslim. If the owner states that copying for benefit is not allowed, this means it is permitted to have some special copy for private use. But, if he does not give any permission, then it is Haram to copy by any means and ways. Other scholars believe that it is Halal to copy these CDs as long as for private and not for trading purposes, especially for students who need these CDs and do not find the original copy or even the money to buy them. However, the safest position for a Muslim is to avoid buying or using copied CDs, nor to copy them. If it becomes difficult to find the original copies, then there is no harm to buy copied ones, provided that does not lead one to vow falsely.

\section{SOFTWARE PIRACY PROPOSED SOLUTION: DIFFERENT STRATEGIES FOR DIFFERENT CULTURES!}

A priceless tool in combating piracy is the understanding of different cultures and how their social rules work. Most countermeasures for dealing with software piracy are focusing on the western, individualistic, cultures. On the other hand, we have the most collectivistic cultures where sharing is a virtue and is expected by the members of the group.

Software is no exception. A few sales are made, and then copies of the original software are passed on to others. Some even claim that no legitimate copies are needed at all to supply an entire country with a software package.

Instead of trying to impose laws inspired by western culture it would probably prove more effective to alter the method of payment for software for more collectivistic cultures. Many online computer games have applied a monthly subscription fee, which is something that could also be applied to any other software package and instead reduce or completely remove the initial cost of purchase.

By taking this measure, the usefulness of the software package is limited to the individual purchasing the product and without imposing any new piracy laws and regulations which in the end will minimize the act of software piracy among these societies. 


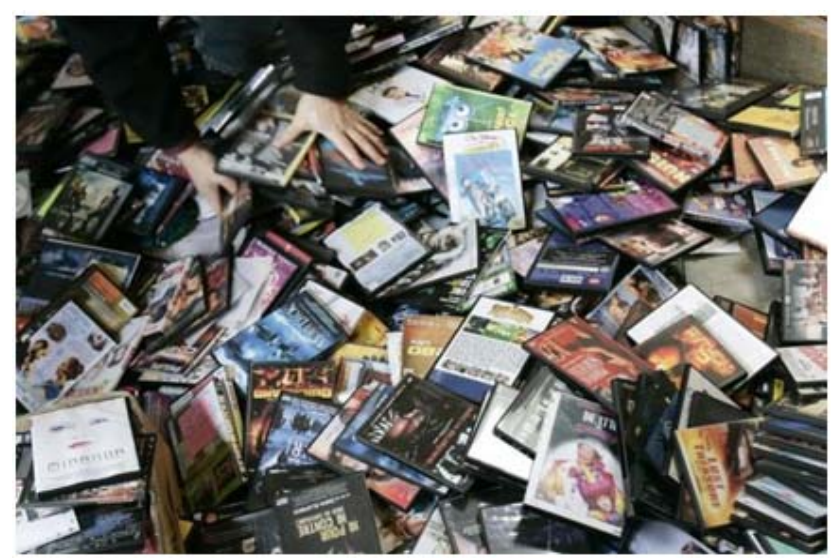

Figure 14: In Some Regions, Pirated Software Is a Way Of Life

\section{CONCLUSION \& FINAL THOUGHTS}

Software piracy is a serious issue that impacts the bottom line for software developers. By implementing a security plan for software protection, software developers gain the benefits of protection from piracy as well as obtain the ability to implement additional license models. (A security implementation plan that balances the time and resources with the desired outcome is possible given the wide range of security options. Developers can additionally choose a phased approach to the security implementation if time or resources are constrained in the short term.

Throughout this paper we have taken a close look at software and digital media piracy both from a historical perspective as well as the modern situation. The publics craving for software and digital media has never been greater and I feel that the industry should embrace the interest and focus on eliminating the hostility towards the gigantic corporations. Instead, they should strive towards creating a feeling of unity with the public and make the customer feel important rather than being considered a potential thief.

\section{REFERENCES}

[1] Quran and Hadith .

[2] Abdul Ghani Azmi, I., M., The Philosophy of Intellectual Property Rights over Ideas in Cyberspace: A Comparative Analysis between the Western Juriprudence and the Sharai’ah, 19 Arab Law Quarterly 191-208, 2004. 
[3] Al-A'ali, M. , "Computer Ethics for the Computer Professional from an Islamic Point of View," Journal of Information, Communication and Ethics in Society, vol. 6(1), pp. 28-45, 2008.

[4] Al-Fadhli, S. , "The Ethical Dilemma of Software Piracy in Islamic Societies: The Case of Kuwait,” The Electronic Journal on Information Systems in Developing Countries, vol. 39(7), pp. 1-9, 2009.

[5] Al-Rafee, S., \& Rouibah, K. , "The Fight Against Digital Piracy: An Experiment,” Telematics and Informatics, vol. 27, pp. 283-292, 2010.

[6] Al-'Uthaimeen, M. (n.d.). [Online]. Available: http://islamqa.info/en/ref/454. [Accessed March 2013].

[7] Baydoun, N., Mamman, A. and Mohmand, A. , "The religious context of management practices: The case of the Islamic religion. Accounting, Commerce and Finance,” The Islamic Perspective Journal, vol. 3(1 \& 2), pp. 59-79, 1999.

[8] Bin Baz, A.A. (n.d.), “Committee Fatwa: Jurisprudence and Islamic Rulings. In http://islamqa.info/,”[Online]. Available: http://islamqa.info/en/ref/454. [Accessed March 2013].

[9] B. S. A. (. \&. I. D. C. (. G. PC, "The Seventh Annual BSA/IDC Global Software Piracy Study,” 2009.

[10] Chapra, U. M., "Islam and the economic challenge,” Leicester. Islamic Foundation, 1992.

[11] Cooper, C., “The Real Cost of Software Piracy,” Information Age, vol. 6 No. 2, pp. 98-102, 1984.

[12] F. (n.d.), "http://foss.org.my. In Free and Open Source Software,” [Online]. Available: http://foss.org.my/about-foss. [Accessed April 2013].

[13] Glass, A. J., \& Saggi, K., "Intellectual property rights and foreign direct investment,” Journal of International Economics, vol. 56(2), pp. 387-410, DOI:10.1016/S0022-1996(01)00117-9, 2002.

[14] Hamid, A. H., "Islam the natural way,” A. S. Noordeen, Kuala Lumpur, 1999.

[15] Naik, Z., "World News. In http://wn.com,” 2010. [Online]. Available: http://wn.com/zakir_naik_using_pirated_software. [Accessed April 2013].

[16] Shahul, H. M. I, "Paper presented as the Asia Pacific Conference 1,” in Islamic accounting - Accounting for the new millennium?, Kota Bharu, Malaysia, 2001.

[17] West, J., “Software right and Japan's shift to an information society,” Asian Survey, vol. 35 No. 12, pp. 18-39, 1995.

[18] Zaineddin, S., "Intellectual Property Rights from an Islamic perspective," International Journal of Intellectual Property Management, vol. 2(2), pp. 130138, 2008. 